\title{
Usefulness of endoscopic ultrasonography in the preoperative diagnosis of submucosal digestive tumours
}

\author{
D. Martínez-Ares, J. Souto-Ruzo, J. Yáñez López and J. L. Vázquez Iglesias \\ Department of Gastroenterology. Complejo Hospitalario Universitario Juan Canalejo. A Coruña, Spain
}

\begin{abstract}
Introduction: the preoperative diagnosis of submucosal lesions in the gut may be complicated. Conventional endoscopy does not allow to clearly establishing a diagnosis, and does not adequately assess lesion size. Furthermore, endoscopic biopsy is usually not diagnostic. Cytology as performed by means of fineneedle puncture does not have enough sensitivity and specificity to be considered the gold standard in the diagnosis of these lesions. We will now assess the usefulness of endoscopic ultrasonography in the study of submucosal digestive tumors.

Materials and methods: we have prospectively collected ultrasonographic studies from all the patients with submucosal tumors who were treated surgically. We assessed the sensitivity and specificity of this technique in the diagnosis of malignancy in said lesions, alongside factors that predict malignant behavior with the highest reliability. We also valued the reliability of ultrasound endoscopy in the assessment of lesion size and the wall layer where lesions are located. The results of histological studies were considered the gold standard.
\end{abstract}

Results: the average size of lesions as measured by ultrasound endoscopy was $37.42 \mathrm{~mm}$, with no significant differences in surgical piece: 38.98 ( $p=0.143$ ). However, conventional endoscopy underestimates the size of lesions. Endoscopic ultrasonography was able to adequately establish the origin layer of lesions in all cases. Sensitivity, specificity, positive predictive val$\mathrm{ue}$, and negative predictive value of ultrasound endoscopy in the diagnosis of malignancy were $89.5,90.9,89.5$, and $90.9 \%$, respectively. In the univariate analysis, the ultrasonographic characteristics associated with a diagnosis of malignancy included presence of ulceration $(p=0.043)$, size above $4 \mathrm{~cm}(p=0.049)$, irregular edges of lesion ( $p=0.0001)$, a heterogeneous ultrasonographic pattern $(p=0.002)$, and the presence of cystic areas above $2 \mathrm{~mm}(\mathrm{p}=0.012)$. In the multivariate analysis, the last three factors were considered independent predictive factors for malignancy.

Conclusions: endoscopic ultrasonography has a great sensitivity and specificity in the diagnosis of malignancy regarding sub-

\section{Recibido: 10-05-04}

Aceptado: 04-01-05.

Correspondencia: David Martínez Ares. C/ Gerona, 3, 2 B. 36211 Vigo, Pontevedra mucosal lesions. The irregularity of lesion borders, a heterogeneous ultrasonographic pattern, and the presence of cystic areas above $2 \mathrm{~mm}$ in size were considered independent predictive factors for malignancy.

Key words: Submucosal tumors. Endoscopic ultrasonography. Malignancy. Endoscopy. Diagnosis.

Martínez-Ares D, Souto-Ruzo J, Yáñez López J, Vázquez Iglesias JL. Usefulness of endoscopic ultrasonography in the preoperative diagnosis of submucosal digestive tumours. Rev Esp Enferm Dig 2005; 97: 416-426.

\section{INTRODUCTION}

Submucosal lesions of the gut are those appearing in any of the layers underneath the mucosa and growing in such a way that the latter layer remains intact. Lesions may be intraparietal (submucosal tumors proper) or display extraparietal growth, which behaves as an extrinsic compression (1).

Gastrointestinal tumors are mainly of epithelial nature (originating in the mucosa), and hence submucosal tumors account for only $1-2 \%$ of their total number $(2,3)$; they are mostly benign, but up to $20 \%$ may display a malignant behavior (2).

In most cases these lesions are asymptomatic and their diagnosis is incidentally reached during endoscopic examinations indicated for other reasons $(1,2,4,5)$. They are rarely the cause of gastrointestinal hemorrhage when associated with ulceration; when tumors reach a considerable size they may cause pain or even lead to the compression of adjacent organs. In locations such as the cardia or pylorus they may result in gut obstruction because of the reduced diameter of the gut in these points $(2,4,5)$. 
During endoscopic examination, nodular lesions are usually found impacting on the mucosa - which usually remains intact- and thus partially protruding into the gut lumen (1). Conventional endoscopy allows to accurately assessing lesion location, mucosal appearance (normal, friable, transparent, ulcerated,...), and lesion consistency; finally, in some cases it may even render excision easier. Nevertheless, conventional endoscopy does not contribute enough information on the nature of the lesion in most cases, assesses size deficiently, and has difficulties to differentiate between intraparietal lesions and extrinsic compression $(1,4,6)$. Furthermore, endoscopic biopsy rarely attains enough depth to ensure a diagnosis $(1,7)$. Cytology obtained by means of fine needle aspiration (FNA) puncture under ultrasonographic guidance does not contribute much information either (3,4,8-10), even though the addition of immunohistochemistry techniques significantly improves the diagnostic performance of this technique (11-14). Nevertheless, many authors consider that in order to obtain an accurate diagnosis with regard to malignancy degree - which will be based on criteria like tumor size, cellularity, number of mitoses, growth pattern, existence of cohesive fibers, and nuclear pleomorphism (15)- it will be essential that the complete piece is available. Thus, there is virtually generalized agreement that the most adequate method to reach a definitive diagnosis is surgical or endoscopic extirpation when in doubt regarding the potential nature of a submucosal lesion, (1621). On the other hand, endoscopic ultrasonography (EUS) will be the most appropriate technique to decide whether a lesion is subsidiary of resection, and if so, which is the safest way to excise it $(4,22,23)$. In cases in which endoscopic resection is not feasible, the lesion's ultrasonographic appearance may suggest a diagnosis of malignancy and, in such a case, surgical resection would be essential.

We will now asses the role that EUS may play in the preoperative diagnosis of submucosal lesions. In order to do so, we will study the sensitivity and specificity of EUS in the diagnosis of malignancy, and will also try to assess which features have the highest predictive power for malignancy.

\section{PATIENTS AND METHOD}

\section{Patients}

Patients were recruited prospectively amongst those referred to our center for ultrasound endoscopy during the period from January $1^{\text {st }} 1996$ to December $31^{\text {st }} 2002$ following the identification of submucosal lesions in their digestive tract. We selected those for whom surgical treatment had been indicated.

\section{Method}

Ultrasonographic studies were conducted using Olympus GF-UM 160 and GF-UM 20 radial ultrasound gastro- scopes, and an Olympus CF-UM 20 radial echocolonoscope. All patients were studied in a single center, and screening tests were conducted by two experts in ultrasound endoscopy.

\section{Variables studied}

In each patient a series of variables were studied, which included demographic variables, clinical manifestations stemming from lesions, endoscopic appearance (size, shape and presence or absence of ulceration), ultrasonographic characteristics (size, edge definition, echogenicity, presence of adenopathies, and presence of cystic areas or hyperechogenic foci inside), reasons for the indication of surgical treatment, complications, histological diagnosis of benignity or malignancy and definitive diagnosis of lesions, presence of adenopathies, infiltration growth, and vascular invasion. The preoperative diagnosis of malignancy was based on the presence of at least three of the following characteristics: ulceration, irregular edges, size greater than $4 \mathrm{~cm}$, heterogeneous echogenicity, presence of cystic areas, presence of hyperechogenic foci, and presence of adenopathies.

\section{Statistical study}

The statistical study was conducted by means of the statistics software package SPSS for Windows 11.5. Statistical significance was established according to the Chi square test $\left(\chi^{2}\right)$ when qualitative variables were compared, whereas quantitative variables were compared by means of the coupled t Student test. Finally, the multivariate analysis was conducted by means of the binary logistic regression method.

Findings described in the histological study of the resection piece were considered the gold standard for the diagnosis of malignancy in lesions, as well as for the assessment of their size and the wall layer in which submucosal lesions were located.

Data corresponding to sensitivity, specificity, positive predictive value, and negative predictive value were calculated manually after classifying ultrasonographic diagnoses of benignancy and malignancy as true positives or true negatives in a $2 \times 2$ table.

\section{RESULTS}

The group consisted of a total of 41 patients, 28 males $(68.3 \%)$ and 13 females $(31.7 \%)$ with an average age of 53.2 years (19-81 range). The majority of lesions were located in the upper digestive tract: $70.7 \%$ in the stomach, $19.5 \%$ in the esophagus, and $7.3 \%$ in the duodenum. One lesion was located in the colon; $46.3 \%$ of patients visited their doctors for dyspepsia, and $29.3 \%$ had upper 
digestive hemorrhage; half of patients with esophageal lesions $(9.8 \%)$ had dysphagia, and other rarer clinical manifestations developed in the rest of patients (Table I).

Tumor characteristics are summarized in table I: $78 \%$ of lesions had a nodular shape, whereas only 5 patients

Table I. Clinical, endoscopic, ultrasound and pathological features of surgically treated submucosal tumors

\begin{tabular}{|c|c|}
\hline Characteristics & Frequency \\
\hline Number of patients & 41 \\
\hline Average age & $53.2(19-81)$ \\
\hline \multicolumn{2}{|l|}{ Sex } \\
\hline Male & $28(68.3 \%)$ \\
\hline Female & $13(31.7 \%)$ \\
\hline \multicolumn{2}{|l|}{ Clinical manifestations } \\
\hline Upper gastrointestinal bleeding & $12(29.3 \%)$ \\
\hline Dyspepsia & $19(46.3 \%)$ \\
\hline Dysphagia & $4(9.8 \%)$ \\
\hline Other manifestations & $5(14.6 \%)$ \\
\hline \multicolumn{2}{|l|}{ Location of lesions } \\
\hline Stomach & $29(70.7 \%)$ \\
\hline Esophagus & $8(19.5 \%)$ \\
\hline Duodenum & $3(7.3 \%)$ \\
\hline Colon & $1(2.4)$ \\
\hline \multicolumn{2}{|l|}{ Morphology of lesions } \\
\hline Nodular & $32(78 \%)$ \\
\hline Polypoid & $5(12.2 \%)$ \\
\hline Umbilicated & $4(9.8 \%)$ \\
\hline \multicolumn{2}{|l|}{ Ultrasound endoscopy features } \\
\hline Ulceration & $20(48.8 \%)$ \\
\hline \multicolumn{2}{|l|}{ Ultrasonographic layer } \\
\hline Second & $3(7.3 \%)$ \\
\hline Third & $4(9.8 \%)$ \\
\hline Fourth & $32(82.9 \%)$ \\
\hline Lesion size & $38.98(8-80) \mathrm{mm}$ \\
\hline Above $4 \mathrm{~cm}$ & $18(43.9 \%)$ \\
\hline Above $3 \mathrm{~cm}$ & $25(61 \%)$ \\
\hline Irregular edges & $11(26.8 \%)$ \\
\hline \multicolumn{2}{|l|}{ Echogenicity } \\
\hline Hyperechogenic & $3(7.3 \%)$ \\
\hline Isoechogenic & $2(4.9 \%)$ \\
\hline Hypoechogenic & $30(73.2 \%)$ \\
\hline Mixed & $6(14.6 \%)$ \\
\hline Heterogeneous echogenicity & $18(43.9 \%)$ \\
\hline Adenopathies & 0 \\
\hline Cystic areas & $12(29.3 \%)$ \\
\hline Hyperechoic areas & $7(17.1 \%)$ \\
\hline Malignancy ultrasound diagnosis & $19(46.3 \%)$ \\
\hline \multicolumn{2}{|l|}{ Indication of surgical treatment } \\
\hline Malignancy ultrasound diagnosis & $18(43.9 \%)$ \\
\hline Clinical complications & $13(31.7 \%)$ \\
\hline Patient choice & $6(14.6 \%)$ \\
\hline Impossible endoscopic resection & $4(9.8 \%)$ \\
\hline Histological malignancy diagnosis & $18(43,9 \%)$ \\
\hline \multicolumn{2}{|l|}{ Most frequent diagnoses } \\
\hline Leiomyoma & $14(34.1 \%)$ \\
\hline GIST & $8(19.5 \%)$ \\
\hline Aberrant pancreas & $5(12.2 \%)$ \\
\hline Leiomyosarcoma & $4(9.8 \%)$ \\
\hline Sarcoma & $3(7.3 \%)$ \\
\hline Lypoma & $3(7.3 \%)$ \\
\hline Other diagnoses & $4(9.8 \%)$ \\
\hline
\end{tabular}

had polypoid lesions, which were umbilicated in 4 patients. In 20 patients $(48.8 \%)$ lesions were ulcerated; $82.9 \%$ of lesions were near the forth layer of the wall, $9.8 \%$ were within the third layer, and $7.3 \%$ were located in the second layer. Ultrasonography was able to correctly establish the layer on which the lesion originated in all cases.

Average size of lesions as measured by ultrasound endoscopy was $37.42 \mathrm{~mm}$, slightly inferior to the size reported by the pathologic study, $38.98 \mathrm{~mm}$, even if this difference was not statistically significant $(p=0.143)$. Nevertheless, the average size of lesions as measured by conventional endoscopy was $34.1 \mathrm{~mm}$, which is significantly smaller than histological findings $(p=0.002)$. In 18 cases these lesions (43.9\%) had a size bigger than 40 $\mathrm{mm}$. The remaining features assessed during the ultrasound endoscopy study, including those assessed without reaching a malignancy diagnosis, are also summarized in table I. We should not forget to mention that in our series adenopathies were never observed after the ultrasonographic study, and they were only seen in the piece in one patient. According to these characteristics, a diagnosis of malignancy was reached in 19 cases (46.3\%).

Surgical treatment was conducted in 18 cases $(43.9 \%)$ for a preoperative diagnosis of malignancy; in 13 cases $(31.7 \%)$ for a very expressive manifestation of hemorrhage or intense pain; in 6 cases the patient preferred open surgery to endoscopic resection; and in 4 cases the characteristics of the tumor did not advise endoscopic resection: in one case it was a big tumor (42 $\mathrm{mm})$; in another patient in whom a carcinoid tumor was found after ultrasound endoscopy, the study itself showed the presence of big arterial vessels close to the tumor. Finally, in two cases lesions were located within the fourth layer of the wall.

After histological study the presence of 18 malignant lesions was confirmed. The most common tumor type was leiomyoma (34.1\%), followed by GIST (19.5\%) (Fig. 1), aberrant pancreas (12.2\%), leiomyosarcoma (9.8\%) (Fig. 2), sarcoma (7.3\%), and lymphoma (7.3\%). Two leiomyomas were considered malignant by the ultrasound endoscopist (false positives), whereas a leiomyosarcoma and a sarcoma were considered benign (false negatives). From this we can infer that, in our experience, USE has a sensitivity of $89.5 \%$, a specificity of $90.9 \%$, a positive predictive value of $89.5 \%$, and a negative predictive value of 90.9\% (Table II).

In the univariate analysis (Table III) of the features assessed for a possible diagnosis of malignancy the presence of ulceration $(\mathrm{p}=0.043)$, size above $4 \mathrm{~cm}(\mathrm{p}=$ $0.049)$, irregularity of lesion edges $(\mathrm{p}=0.0001)$, heterogeneous ultrasonographic pattern $(\mathrm{p}=0.002)$, and presence of cystic areas bigger than $2 \mathrm{~mm}(\mathrm{p}=0.012)$ reached statistical significance. Table IV depicts the relative risk for malignancy entailed by these ultrasonographic and endoscopic characteristics. Of note, the highest risk is associated with the presence of irregular edges, a heteroge- 


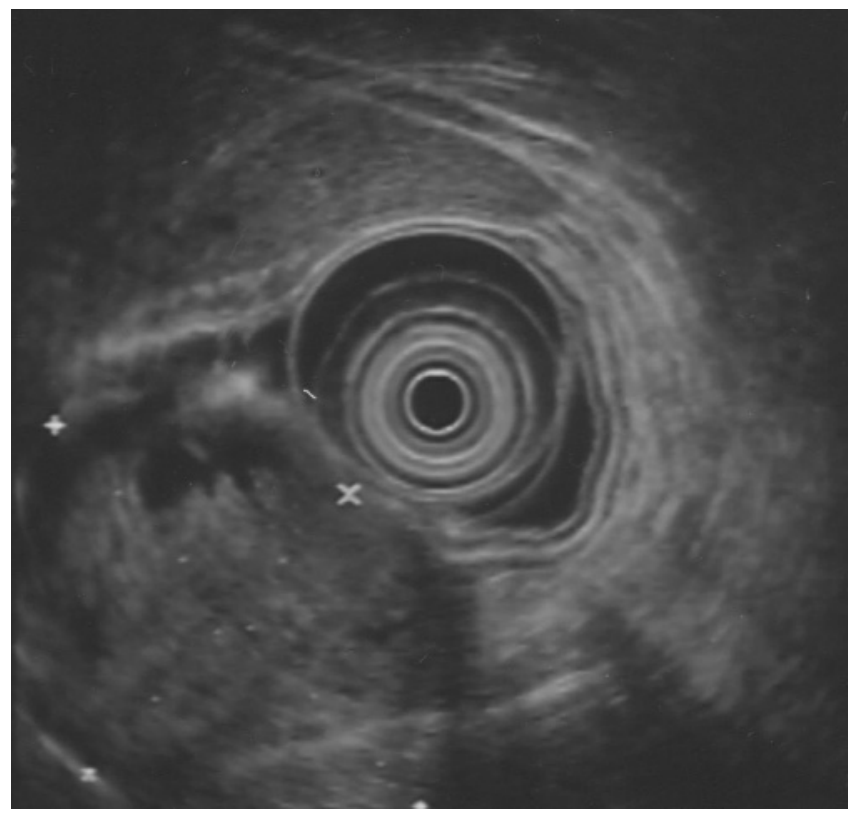

Fig. 1.- Image showing a blurry-edge lesion with a heterogeneous ultrasound pattern and the presence of cystic areas inside. The pathologic diagnosis was malignant GIST.

En la imagen se objetiva una lesión de bordes mal definidos, con un patrón ecográfico heterogéneo y con presencia de áreas quísticas en su interior. El diagnóstico anátomopatológico fue de GIST maligno.

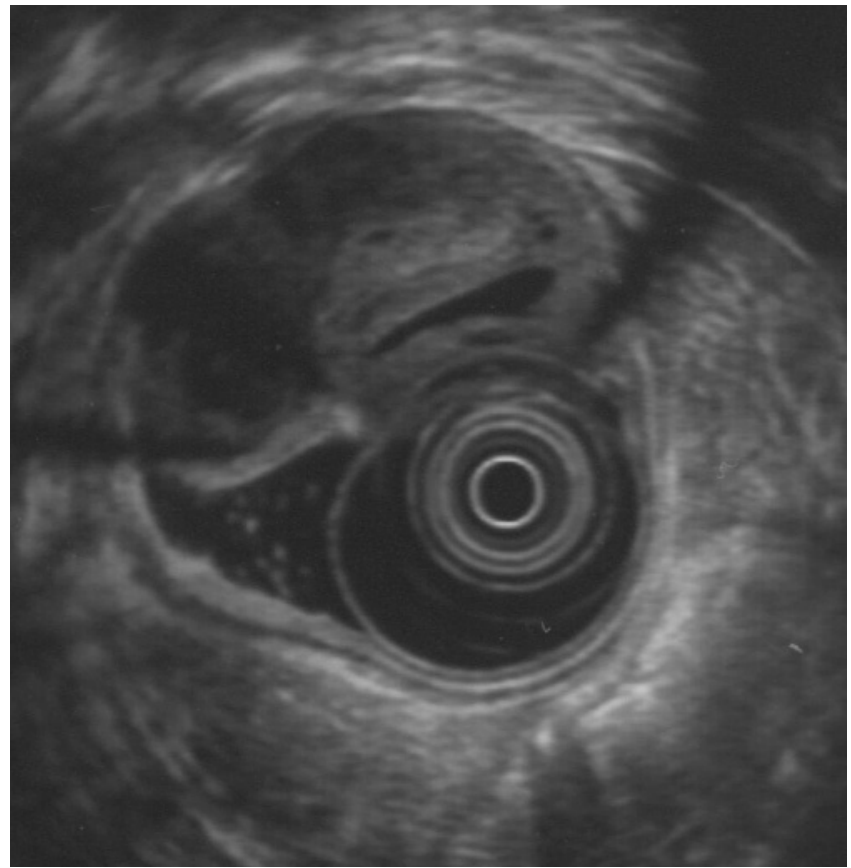

Fig. 2.- Image showing the presence of a lesion with ultrasonographic malignancy features; histological diagnosis was gastric leiomyosarcoma.

En la imagen observamos la presencia de una lesión con características ultrasonográficas de malignidad, cuyo diagnóstico histológico fue de un leiomiosarcoma gástrico.
Table II. Summary of the results of preoperative diagnosis based on ultrasound endoscopy

\begin{tabular}{lccc}
\hline & $\begin{array}{c}\text { Malignant } \\
\text { tumors }\end{array}$ & $\begin{array}{c}\text { Benign } \\
\text { tumors }\end{array}$ & Total \\
\hline USE malignancy diagnosis & 17 & 2 & 19 \\
USE benignancy diagnosis & 2 & 20 & 22 \\
Total & 19 & 22 & 41 \\
\hline
\end{tabular}

From them we can calculate a sensitivity of $89.5 \%$, a specificity of $90.9 \%$, a positive predictive value of $89.5 \%$, and a negative predictive value of $90.9 \%$

Table III. Summary of the ultrasonographic and endoscopic features of lesions and their association with malignant behavior

\begin{tabular}{lccc}
\hline $\begin{array}{l}\text { Endoscopic and ultrasound } \\
\text { features associated with } \\
\text { malignancy }\end{array}$ & \multicolumn{2}{c}{ Frequency (\%) } & \\
Benign & Malignant & p \\
\hline Ulceration & 34.7 & 66.7 & 0.043 \\
Size above 4 cm & 30.4 & 61.1 & 0.049 \\
Adenopathies & 0 & 0 & \\
Irregular edges & 4.3 & 55.6 & 0.0001 \\
Heterogeneous echogenicity & 21.7 & 72.2 & 0.002 \\
Cystic areas & 13.05 & 50 & 0.012 \\
Hyperechogenic areas & 8.6 & 27.8 & 0.118 \\
\hline
\end{tabular}

Table IV. Relative malignancy risks associated with each of the ultrasonographic and endoscopic characteristics of submucosal tumors

\begin{tabular}{lccl}
\hline Characteristic & Relative risk & IC to $\mathbf{9 5 \%}$ & Significant \\
\hline Ulceration & 3.75 & $1.02-13.79$ & Significant \\
Size above 4 cm & 3.59 & $1.02-14.9$ & Significant \\
Adenopathies & 0 & 0 & \\
Irregular edges & 27.5 & $3.01-250.7$ & Significant \\
Heterogeneous echogenicity & 9.35 & $2.23-39.13$ & Significant \\
Cystic areas & 6.66 & $1.50-30.64$ & Significant \\
Hyperechogenic areas & 4.02 & $0.68-23.9$ & NS \\
\hline
\end{tabular}

neous ultrasound pattern, and the presence of cystic areas inside the lesions. After conducting a multivariate analysis, these three factors were considered independent predictive factors for malignancy.

\section{DISCUSSION}

Conventional endoscopy has great limitations in the assessment of submucosal digestive lesions. The adequate assessment of their size and especially the establishment of a diagnosis are not usually possible $(1,4,6)$. Knowing the etiology of the lesion is of vital importance, since many patients will be asymptomatic and the decision to excise the lesion will depend thereupon. On the 
other hand, biopsies taken during the endoscopic examination are rarely diagnostic, since the mucosa is usually intact and biopsy forceps do not usually attain enough depth $(1,4,6,7)$. Furthermore, the cytology obtained by means of FNA puncture before the development of modern immunohistochemistry techniques had limited diagnostic profitability $(3,4,8-10)$, which is clearly superior in the study of adenopathies and extramural lesions (10). Nevertheless, the study of cytology samples by applying immunohistochemistry techniques considerably increases diagnostic accuracy (12-14). Furthermore, the introduction of the c-Kit study seems to be greatly reliable in the diagnosis of malignancy (12). In any case, most authors agree on the fact that the diagnosis of malignancy is based on criteria such as the size of the lesion, cellularity, presence of mitoses, absence of an organoid growth pattern, absence of skeletal fibers, nuclear pleomorphism, involvement of the overlying mucosa, and cellular necrosis, many of which could only be established after an overall study of the piece.

EUS has been given a central role in the study of these lesions right from their origin. Thus, when average lesion size as measured by ultrasound endoscopy exceeded 30 $\mathrm{mm}$ or grew more than $5 \mathrm{~mm}$ per year, or if the diagnosis was doubtful, extirpation was indicated. Furthermore, ultrasound endoscopy may suggest the technique of choice for resection: endoscopic or surgical $(4,22-24)$. In fact, EUS has shown great reliability in the study of submucosal lesions. First of all, it has great sensitivity and specificity for the differentiation of these lesions from extrinsic compression (4,25-29). Furthermore, it clearly distinguishes between solid and cystic masses (1). Previous studies $(24,30)$ had proven that USE allowed differentiation of layers in the gut wall, and therefore a clear definition of the layer in which a tumor actually originates. In our series, surgically treated tumors were mainly dependent on the fourth layer, which was correctly established by USE in all cases.

Tumor size is also adequately assessed by USE. Only very bulky tumors exceeding the vision field and thus impeding adequate measurement may be deficiently assessed (25). In our series, ultrasound endoscopy established the size of lesions quite accurately, whereas the average size of lesions as measured by conventional endoscopy was significantly smaller than the resection piece.

Many papers have been published in which we may see how USE can suggest the nature of submucosal lesions in a quite reliable manner $(4,21,24,31-35)$. Several studies have also been published in which the sensitivity of ultrasound endoscopy was assessed in the diagnosis of malignancy $(2,23,26,27)$. In the study by Rosch et al. (26), sensitivity and specificity figures were 64 and $84 \%$, respectively, which was significantly lower than those published by other authors and those in our series. In the studies conducted by Chak et al. (2) and Brand et al. (27), sensitivity and speci- ficity figures would be around $80 \%$, and in that by Palazzo et al. (23) around $90 \%$. In our series, conducted on 41 surgically-intervened tumors, sensitivity was $89.5 \%$, specificity $90.9 \%$, positive predictive value $89.55 \%$, and negative predictive value $90.9 \%$. It is important to highlight the fact that ours is the only study in which figures were calculated before the assessment of factors predicting malignancy. In our case, the diagnosis of malignancy is established beforehand when at least three of the following features are present: ulceration, size bigger than $40 \mathrm{~mm}$, irregular lesion edges, heterogeneous echogenicity, presence of cystic spaces, presence of hyperechogenic foci, and adenopathies. In all the remaining studies, sensitivity and specificity were calculated after assessing and combining factors that best predicted malignant behavior. In the study by Chak et al. (2) the authors considered as factors predicting malignancy a size bigger than $40 \mathrm{~mm}$, irregularity in lesion edges, presence of hyperechogenic foci, and cystic spaces. In this study, in which only 9 malignant lesions were seen, the presence of hyperechogenic foci attained statistic significance contrary to our series, while two factors are not considered to be predictive of malignancy, even if our experience shows that they are indeed significant: presence of ulceration and a heterogeneous ultrasound pattern. In the study by Brand et al. (27) the following were considered independent malignancy-predictive factors: a size bigger than $3 \mathrm{~cm}$, presence of irregular edges, and heterogeneous ultrasound pattern. Presence of ulceration and presence of cystic spaces did not reach statistical significance. Finally, Palazzo et al. (23) exclusively considered that independent malignancy-predictive factors included presence of cystic spaces and irregular extraluminal edges. It looks as if there is more agreement with regard to these two factors. Nevertheless, in our experience a heterogeneous ultrasound pattern should also be considered an independent malignancy-predictive factor, and with a higher number of cases the presence of ulceration and size above $40 \mathrm{~mm}$ would also probably attain statistical significance.

In summary, we claim that conventional endoscopy assesses submucosal lesions in a deficient manner, and that USE accurately establishes the lesion's size, layer of origin, and benign or malignant nature.

\section{REFERENCES}

1. Arguello L, Pellise M, Miquel R. Utility of echoendoscopy in the evaluation of submucosal tumors and extrinsic compressions of the digestive tract. Gastroenterol Hepatol 2002; 25 (1): 13-8.

2. Chak A, Canto MI, Rosch T, Dittler HJ, Hawes RH, Tio TL, et al. Endosonographic differentiation of benign and malignant stromal cell tumors. Gastrointest Endosc 1997; 45 (6): 468-73.

3. Dodd LG, Nelson RC, Mooney EE, Gottfried M. Fine-needle aspiration of gastrointestinal stromal tumors. Am J Clin Pathol 1998; 109 (4): 439-43. 
4. Chak A. EUS in submucosal tumors. Gastrointest Endosc 2002; 56 (4 Supl.): S43-8.

5. Suster S. Gastrointestinal stromal tumors. Semin Diagn Pathol 1996; 13 (4): 297-313.

6. Catalano MF. Endoscopic ultrasonography in the diagnosis of submucosal tumors: need for biopsy. Endoscopy 1994; 26 (9): 788-91.

7. Caletti G, Zani L, Bolondi L, Brocchi E, Rollo V, Barbara L. Endoscopic ultrasonography in the diagnosis of gastric submucosal tumor. Gastrointest Endosc 1989; 35 (5): 413-8.

8. Giovannini M, Seitz JF, Monges G, Perrier H, Rabbia I. Fine-needle aspiration cytology guided by endoscopic ultrasonography: results in 141 patients. Endoscopy 1995; 27 (2): 171-7.

9. Gu M, Ghafari S, Nguyen PT, Lin F. Cytologic diagnosis of gastrointestinal stromal tumors of the stomach by endoscopic ultrasoundguided fine-needle aspiration biopsy: cytomorphologic and immunohistochemical study of 12 cases. Diagn Cytopathol 2001; 25 (6): 343-50

10. Wiersema MJ, Vilmann P, Giovannini M, Chang KJ, Wiersema LM Endosonography-guided fine-needle aspiration biopsy: diagnostic accuracy and complication assessment. Gastroenterology 1997; 112 (4): 1087-95.

11. Li SQ, O'Leary TJ, Buchner SB, Przygodzki RM, Sobin LH, Erozan YS, et al. Fine needle aspiration of gastrointestinal stromal tumors. Acta Cytol 2001; 45 (1): 9-17.

12. Ando N, Goto H, Niwa Y, Hirooka Y, Ohmiya N, Nagasaka T, et al. The diagnosis of GI stromal tumors with EUS-guided fine needle aspiration with immunohistochemical analysis. Gastrointest Endosc 2002; 55 (1): 37-43.

13. Fu K, Eloubeidi MA, Jhala NC, Jhala D, Chhieng DC, Eltoum IE. Diagnosis of gastrointestinal stromal tumor by endoscopic ultrasoundguided fine needle aspiration biopsy -a potential pitfall. Ann Diagn Pathol 2002; 6 (5): 294-301.

14. Gu M, Nguyen PT, Cao S, Lin F. Diagnosis of gastric glomus tumor by endoscopic ultrasound-guided fine needle aspiration biopsy. A case report with cytologic, histologic and immunohistochemical studies. Acta Cytol 2002; 46 (3): 560-6.

15. Brainard JA, Goldblum JR. Stromal tumors of the jejunum and ileum: a clinicopathologic study of 39 cases. Am J Surg Pathol 1997; 21 (4): 407-16.

16. Waxman I, Saitoh Y, Raju GS, Watari J, Yokota K, Reeves AL, Kohgo Y. High-frequency probe EUS-assisted endoscopic mucosal resection: a therapeutic strategy for submucosal tumors of the GI tract. Gastrointest Endosc 2002; 55 (1): 44-9.

17. Kawamoto K, Yamada Y, Furukawa N, Utsunomiya T, Haraguchi Y, Mizuguchi M, et al. Endoscopic submucosal tumorectomy for gastrointestinal submucosal tumors restricted to the submucosa: a new form of endoscopic minimal surgery. Gastrointest Endosc 1997; 46 (4): $311-7$.

18. Kojima T, Takahashi H, Parra-Blanco A, Kohsen K, Fujita R. Diagnosis of submucosal tumor of the upper GI tract by endoscopic resection. Gastrointest Endosc 1999; 50 (4): 516-22.

19. Hyun JH, Jeen YT, Chun HJ, Lee HS, Lee SW, Song CW, et al. Endoscopic resection of submucosal tumor of the esophagus: results in
62 patients. Endoscopy 1997; 29 (3): 165-70.

20. Wei SC, Wong JM, Shieh MJ, Sun CT, Wang CY, Wang TH. Endoscopic resection of gastrointestinal submucosal tumors. Hepatogastroenterology 1998; 45 (19): 114-8.

21. Hunt GC, Smith PP, Faigel DO. Yield of tissue sampling for submucosal lesions evaluated by EUS. Gastrointest Endosc 2003; 57 (1): 68-72.

22. Shen EF, Arnott ID, Plevris J, Penman ID. Endoscopic ultrasonography in the diagnosis and management of suspected upper gastrointestinal submucosal tumours. Br J Surg 2002; 89 (2): 231-5.

23. Palazzo L, Landi B, Cellier C, Cuillerier E, Roseau G, Barbier JP. Endosonographic features predictive of benign and malignant gastrointestinal stromal cell tumours. Gut 2000; 46 (1): 88-92.

24. Palazzo M, Rouseau G. Écho-endoscopie digestive. París: Masson, 1998. p. 21-7.

25. Rosch T. Endoscopic ultrasonography in upper gastrointestinal submucosal tumors: a literature review. Gastrointest Endosc Clin N Am 1995; 5 (3): 609-14.

26. Rosch T, Kapfer B, Will U, Baronius W, Strobel M, Lorenz R, Ulm K; German EUS Club. Endoscopic ultrasonography. Accuracy of endoscopic ultrasonography in upper gastrointestinal submucosal lesions: a prospective multicenter study. Scand J Gastroenterol 2002; 37 (7): 856-62

27. Brand B, Oesterhelweg L, Binmoeller KF, Sriram PV, Bohnacker S, Seewald S, et al. Impact of endoscopic ultrasound for evaluation of submucosal lesions in gastrointestinal tract. Dig Liver Dis 2002; 34 (4): 290-7.

28. Souquet JC, Bobichon R. Role of endoscopic ultrasound in the management of the submucosal tumors in the esophagus and the stomach Acta Endoscop 1996; 26: 307-12.

29. Gress F, Schmitt C, Savides T, Faigel DO, Catalano M, Wassef W, et al. Interobserver agreement for EUS in the evaluation and diagnosis of submucosal masses. Gastrointest Endosc 2001; 53 (1): 71 6.

30. Takada N, Higashino M, Osugi H, Tokuhara T, Kinoshita H. Utility of endoscopic ultrasonography in assessing the indications for endoscopic surgery of submucosal esophageal tumors. Surg Endosc 1999; 13 (3): 228-30

31. Kameyama H, Niwa Y, Arisawa T, Goto H, Hayakawa T. Endoscopic ultrasonography in the diagnosis of submucosal lesions of the largeintestine. Gastrointest Endosc 1997; 46 (5): 406-11.

32. Geller A, Wang KK, DiMagno EP. Diagnosis of foregut duplication cysts by endoscopic ultrasono-graphy. Gastroenterology 1995; 109 (3): 838-42.

33. Bhutani MS, Hoffman BJ, Reed C. Endosonographic diagnosis of an esophageal duplication cyst. Endoscopy 1996; 28 (4): 396-7.

34. Palazzo L, Landi B, Cellier C, Roseau G, Chaussade S, Couturier D, et al. Endosonographic features of esophageal granular cell tumors. Endoscopy 1997; 29 (9): 850-3.

35. Hizawa K, Iwai K, Esaki M, Suekane H, Inuzuka S, Matsumoto T, et al. Endosonographic features of Brunner's gland hamartomas which were subsequently resected endoscopically. Endoscopy 2002; 34 (12): $956-8$ 